\title{
Acoustic signals and behaviour of Ovalipes trimaculatus in the context of reproduction
}

\author{
G. Buscaino ${ }^{1, *}$, A. Gavio ${ }^{2}$, D. Galvan ${ }^{3}$, F. Filiciotto ${ }^{1}$, V. Maccarrone ${ }^{1}$, G. de Vincenzi ${ }^{1}$, \\ S. Mazzola' ${ }^{1}$, J. M. Orensanz ${ }^{3}$ \\ ${ }^{1}$ National Research Council - Institute for Coastal Marine Environment - Bioacoustics lab, Capo Granitola, Via del Mare 6 , \\ 91021 Torretta Granitola, Campobello di Mazara, TP, Italy \\ ${ }^{2}$ Instituto de Investigaciones Marinas y Costeras (IIMyC, UNMdP-CONICET), Estación Costera J.J. Nágera, \\ Facultad de Ciencias Exactas y Naturales, Universidad Nacional Mar del Plata, Funes 3350, 7600 Mar del Plata, Argentina \\ ${ }^{3}$ Centro Nacional Patagónico (CENPAT -CONICET), Bv. Almirante Brown 2915, Puerto Madryn, Chubut, Argentina
}

\begin{abstract}
This study focused on the acoustic behaviour of the paddle crab Ovalipes trimaculatus (De Haan, 1833) in relation to its reproductive status and behaviour. Paired males and females (demonstrating pre-copulatory behaviour) as well as solitary animals were collected a few hundred metres from the coast of Puerto Madryn (Patagonia, Argentina) and kept in indoor tanks. Synchronized acoustic and video monitoring systems were used to record the acoustic signals and other behaviours of single and grouped specimens in an experimental tank. Acoustic data were analysed to characterize crab sounds (duration, pulse number and pulse rate, 1st and 2nd peaks in frequency, amplitude of the frequency peaks and bandwidth) and were counted as behavioural events. Video data were analysed to count behavioural events (i.e. agonistic fight, chela spread) and determine status (locomotor indices, inter-crab distance). $O$. trimaculatus produced wide frequency band multi-pulse signals with significant differences between males and females: males showed a lower 1st peak in frequency, with a higher amplitude and a higher bandwidth. The sound emission rate was significantly higher in grouped animals than in single individuals. The sound emissions were not accidental events correlated with locomotor activities. In the trials involving pre-copulatory females, the total number of sounds was significantly higher compared to the trials with non-copulatory (control) females, and the sounds were not correlated with the agonistic events between males. Our data indicate that in $O$. trimaculatus sound emissions play a role in intraspecific communication related to sexual attraction.
\end{abstract}

KEY WORDS: Acoustic behaviour $\cdot$ Crabs $\cdot$ Reproductive context

\section{INTRODUCTION}

Many marine animals use acoustic signals to enact a wide range of biological activities. There is good evidence that sound is used as an orientation cue in fish to guide settlement onto reefs (Simpson et al. 2004), and that dolphins use echolocation to search for prey (reviewed by Au 1993, Miller et al. 2004, Johnson et al. 2008, Buscaino et al. 2015). Several species of marine crustaceans have evolved various

\footnotetext{
*Corresponding author: giuseppa.buscaino@cnr.it
}

sound production mechanisms (reviewed by Greenfield 2002, Patek \& Oakley 2003, Buscaino et al. $2011 \mathrm{a}, \mathrm{b})$, such as percussion or rubbing (Imafuku \& Ikeda 1990), stridulation (Boon et al. 2009), carapace vibrations (Patek \& Caldwell 2006), stick and slip friction (Meyer-Rochow \& Penrose 1976, Patek 2001, Patek \& Baio 2007, Patek et al. 2009), snaps (Knowlton \& Moulton 1963), emission of bubbles (Crane 1966), mandible grinding (Meyer-Rochow \& Penrose 1976) and contraction of internal muscles (Henninger

(C) The authors 2015. Open Access under Creative Commons by Attribution Licence. Use, distribution and reproduction are unrestricted. Authors and original publication must be credited. 
\& Watson 2005). However, little is known about the ability of crustaceans to perceive sound and vibration (Meyer-Rochow et al. 1982, de Vincenzi et al. 2015). Many decapods have an extensive array of hair-like receptors that could potentially or actually respond to water displacements (reviewed by Popper et al. 2001) and changes in pressures (Ali 1987), however to date, intraspecific communication in decapods based on acoustic signals is still hypothetical.

Ovalipes trimaculatus (Crustacea, Brachyura, Polybiidae) is a swimming crab adapted to live in highlatitude environments ( 25 to $45^{\circ} \mathrm{S}$; Boschi et al. 1992). It has a wide geographical distribution, dwelling on the sandy bottoms of the east and west coast of South America and South Africa (Arnaud et al. 1972, Nakamura et al. 1986, Boschi et al. 1992, de Melo 1996, Retamal \& Arana 2000) from the low intertidal to about $100 \mathrm{~m}$ depth (Boschi et al. 1992). A more recent study conducted in the San Jorge Gulf (Argentina) (Vinuesa 2005) reported a more limited distribution to $30 \mathrm{~m}$ depth.

Guinot-Dumortier \& Dumortier (1960) hypothesized that Ovalipes spp. produces sounds via stridulation, and that some species of this genus use the friction of their appendices on the cephalothorax or other body regions to synthesize sounds. Stephenson (1969) stated that these stridulatory structures vary in development with the species group, defining ' $\mathrm{A}$ ' and 'B' groups. In O. trimaculatus and $O$. punctatus (both belonging to group 'A'), it was proposed that the sounding body consists of a large ribbed surface on the lower edge of the cheliped, which can rub on a partial horn surrounding the distal end of the merus of the first pair of walking legs (Guinot-Dumortier \& Dumortier 1960). In O. trimaculatus males, these structures are bigger than those of females and likely affect the characteristics of the produced sound. However, the sound emission mechanism and the relative structures involved remains only hypothesized. Although sound production is known to occur in this species, the bio-ecological role of these signal emissions is not yet understood.

Some researchers have assumed that marine crustaceans only produce sounds in the context of antipredator behaviour (Lindberg 1955, Moulton 1957, Hazlett \& Winn 1962, Meyer-Rochow \& Penrose 1974, 1976, Patek 2001, Patek \& Oakley 2003, Bouwma \& Herrnkind 2009). Others have proposed alternative functions that include mate attraction, aggregation, locating feeding individuals, and aggressiveterritorial behaviour (Moulton 1957, Busnel 1963, Stephenson 1969, Meyer-Rochow et al. 1982, Buscaino et al. 2011a,b, de Vincenzi et al. 2015). For instance, McLay (1988) speculated that the sounds produced by $O$. catharus are involved in courtship display, and Parker et al. (1998) hypothesized that Ovalipes spp. use sounds as a sexual signal. Sexual behaviour plays an important role in mate attraction and mating pair formation. Nevertheless, there is neither research on the acoustic signals in the context of mating behaviour of $O$. trimaculatus nor a description of the acoustic parameters that characterize these signals. Information about the context in which the crabs emit acoustic signals is important, because it allows for a greater understanding of the ecological role of these signals. Moreover, the acoustic parameters that characterize the signals, and their energy distribution at different frequencies indicate the potential receivers of these signals, based on their hearing ability (i.e. their audiogram).

In Brachyura, communication during the reproductive period can occur through visual, acoustic, chemical and tactile cues, which may act synergistically (Sastry 1983, Sal Moyano \& Gavio 2012, Sal Moyano et al. 2014). During the reproductive period, several changes occur in the biology of crustacean species with consequent changes in behaviour. For example, Pinheiro \& Fransozo (1999) showed that in courtship exhibitions, males of the swimming crab Arenaeus cribrarius embrace females. They defined this behaviour as a 'precopulatory embrace', during which the male uses its second pereiopod pair to carry the female. Copulation occurs shortly after moulting, when the female has a soft carapace (Asakura 2009). Thus, it is reasonable to assume that some types of signals (chemical, acoustic, visual) occur between males and females to encourage the choice of the pre-moulting female.

In this study, we characterized the acoustic signals emitted by $O$. trimaculatus and examined whether they differed qualitatively and quantitatively between (1) sex, (2) single or grouped individuals, and (3) during the day or the night. We also studied the behavioural context of the acoustic emissions and its relationship to reproductive status.

\section{MATERIALS AND METHODS}

\section{Animal housing and experimental design}

The study was conducted in the marine laboratory tanks at the CENPAT-CONICET in Puerto Madryn (SE Argentina). A total of 100 specimens of Ovalipes trimaculatus were captured in February 2014 by 
snorkelling at a depth of 5 to $10 \mathrm{~m}$ near the beach of Puerto Madryn, including 37 mating pairs, 24 noncopulatory females (control), and 2 non-embracing males. In the mating pairs (with females in the precopulatory embrace), the configuration behaviour indicated that the females were almost ready to moult - a necessary condition for copulation (Crothers 1967, Haddon 1994). After capture, the pairs were separated and placed separately in 8 indoor rectangular PVC tanks $(70 \times 40 \times 28 \mathrm{~cm})$ equipped with an aeration system, and supplied with seawater collected in the Nuevo Gulf (where the animals were captured). The specimens were maintained in holding tanks ( 3 for the 39 males, 3 for the 37 females in the pre-copulatory condition and 2 for the 24 control females) for 1 wk acclimation. The source water supplying the experimental tank had a mean $( \pm \mathrm{SD})$ salinity of $33 \pm 0.1 \mathrm{ppt}$. The temperature was kept constant at $16 \pm 1{ }^{\circ} \mathrm{C}$ during the entire study period by an air-conditioning system. This temperature is similar to that during early summer in the Nuevo Gulf (Dellatorre et al. 2012), where the bottom temperature in shallow water varies between 9 and $19^{\circ} \mathrm{C}$ throughout the year.

Crabs were fed frozen molluscs, shrimps and fish ad libitum and were deprived of food for $2 \mathrm{~d}$ before the start of the experimental trials. All animals were kept under artificial photoperiods $(12 \mathrm{~h}$ light, $12 \mathrm{~h}$ dark). After acclimation, the crabs (39 males and 61 females) were measured (carapace length [mean \pm $\mathrm{SD}$ ] of $80.1 \pm 2.0 \mathrm{~cm}$ [females] and $112.9 \pm 6.3 \mathrm{~cm}$ [males]), and randomly assigned from each group to the 3 experimental trials described below.

The crabs were assigned to the 3 experimental trials described below. Each crab was used in only 1 trial to meet the assumption of experimental independence. For the experimental procedure, we used only crabs that had hard-shelled carapaces. The crabs were released into the centre of a conical PVC experimental tank (Fig. 1) (1 and $0.8 \mathrm{~m}$ diameter at the mouth and at the bottom respectively and $0.5 \mathrm{~m}$ depth). To avoid the noise produced by the crabs' legs during walking, a rubber mat was placed on the bottom of the tank. No shelter was provided.

We analysed different acoustic, locomotor and agonistic behavioural parameters (Table 1) and performed 3 trial typologies (single, group, caged) to study the behaviour and the characteristics of the acoustic signals produced by $O$. trimaculatus. Trials began immediately following $1 \mathrm{~h}$ of acclimation; specimens were monitored for $2 \mathrm{~h}$ (trial duration). In total, we recorded $66 \mathrm{~h}$ of video and $72 \mathrm{~h}$ of acoustic recordings.

\section{Trials}

Single trials: the aim of the single trials was to assess whether single males, single control females, and single pre-copulatory females produced sounds. We also compared the sound emission rate with that of the grouped animals, and assessed other behavioural events and states (see Table 1). A total of 9 trials with single animals were carried out: 3 males alone, 3 control females alone, and 3 pre-copulatory females alone. In total, $18 \mathrm{~h}$ of video and audio data were analysed.

Group trials: the aim of the grouped trials was to assess the differences in behaviours among the different group types and in the acoustic parameters of the emitted sound. We also compared the sound emission rate with that of the single animals. Additionally, for the mixed sex group, we compared the sound emission rate in the daylight with the night. A total of 12 trials in groups of 5 animals were carried out: 9 mono-sex groups ( 3 groups of 5 males, 3 groups of 5 control females, 3 groups of 5 pre-copulatory females) and 3 mixedsex groups (2 pre-copulatory females with 3 males). A total of $24 \mathrm{~h}$ of video and audio data were analysed.

Caged trials: the main aim of these trials was to evaluate whether sound emission rate was related to reproductive context. Moreover, we evaluated the agonistic behaviour of the males (see chelae spread, inter-crab distance and agonistic fight in Table 1) and the distance between the caged females and males.

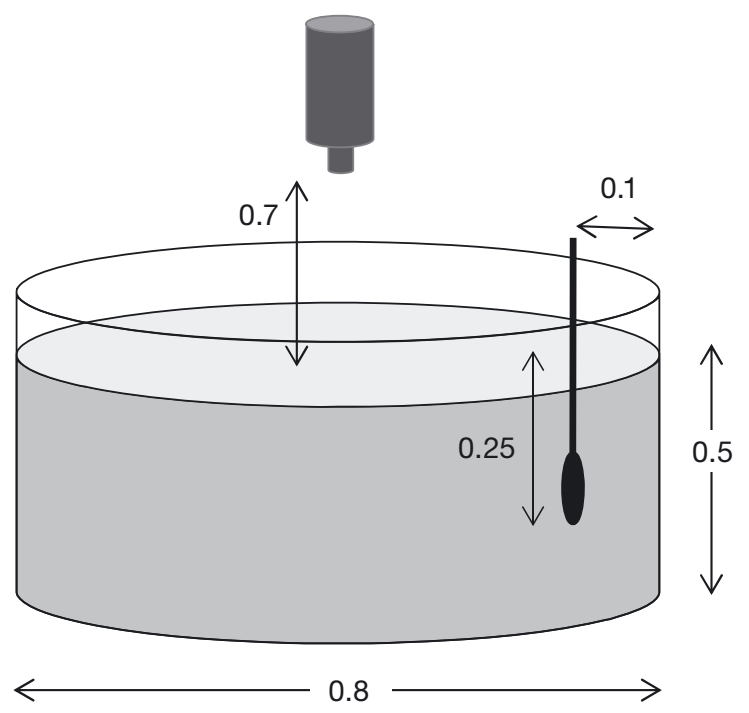

Fig. 1. Schematic representation (in $\mathrm{m}$ ) of the experimental tank equipped with a hydrophone and video camera 
Table 1. Description of Ovalipes trimaculatus behavioural events and states measured during different trials, and the number of hours of data analysed

\begin{tabular}{|c|c|c|c|}
\hline & Description & Trial type & $\begin{array}{l}\text { Hours }(\mathrm{h}) \text { of } \\
\text { video and } \\
\text { acoustic data } \\
\text { analysed }\end{array}$ \\
\hline \multicolumn{4}{|l|}{ Behavioural event } \\
\hline Acoustic signal $^{a}$ & $\begin{array}{l}\text { No. of wide-band frequency multi-pulsed signals } \\
\text { that were likely produced by the stridulating } \\
\text { mechanism (rasp) }\end{array}$ & $\begin{array}{l}\text { All during daylight } \\
\text { Mixed sex group } \\
\text { during night }\end{array}$ & $\begin{array}{l}66 \text { (in daylight) } \\
6 \text { (at night) }\end{array}$ \\
\hline Chela spread $^{\mathrm{a}}$ & No. of threat displays using spread chela & Caged trials & 24 \\
\hline Agonistic fight ${ }^{\mathrm{a}}$ & $\begin{array}{l}\text { No. of fighting by grasping and pulling the } \\
\text { opponent's chela or appendages }\end{array}$ & $\begin{array}{c}\text { Caged trials } \\
\text { (with only } 2 \text { males) }\end{array}$ & 12 \\
\hline Contact approach $^{\mathrm{a}}$ & $\begin{array}{l}\text { No. of contacts with the other male without an } \\
\text { agonistic fight }\end{array}$ & $\begin{array}{c}\text { Caged trials } \\
\text { (with only } 2 \text { males) }\end{array}$ & 12 \\
\hline Contact cage $^{a}$ & $\begin{array}{l}\text { No. of contacts with the cage using any part of } \\
\text { the body }\end{array}$ & Caged trials & 24 \\
\hline \multicolumn{4}{|c|}{ Behavioural status - distances } \\
\hline Inter-crab distance $^{a}$ & $\begin{array}{l}\text { Mean distance }(\mathrm{cm}) \text { between } 2 \text { subjects meas- } \\
\text { ured from the carapace centre point of each crab }\end{array}$ & $\begin{array}{c}\text { Caged trials } \\
\text { (with only } 2 \text { males) }\end{array}$ & 12 \\
\hline Cage-crab distance $^{\mathrm{a}}$ & $\begin{array}{l}\text { Mean distance }(\mathrm{cm}) \text { between the crab and the } \\
\text { cage measured from the centre point of the crab } \\
\text { and the centre point of the cage }\end{array}$ & Caged trials & 24 \\
\hline \multicolumn{4}{|c|}{ Behavioural status - locomotor } \\
\hline Mobility & $\begin{array}{l}\text { Cumulative duration (s) for which animal mean } \\
\text { running velocity is between } 1.50 \text { and } 1.80 \mathrm{~cm} \mathrm{~s}^{-1}\end{array}$ & All & 66 \\
\hline High mobility & $\begin{array}{l}\text { Cumulative duration (s) for which animal mean } \\
\text { running velocity exceeds } 1.80 \mathrm{~cm} \mathrm{~s}^{-1}\end{array}$ & All & 66 \\
\hline Velocity & $\begin{array}{l}\text { Mean distance }\left(\mathrm{cm} \mathrm{s}^{-1}\right) \text { moved by the centre } \\
\text { point of the subject per unit time }\end{array}$ & All & 66 \\
\hline Turn angle & Variation of direction (degree) of the head & All & 66 \\
\hline Angular velocity & $\begin{array}{l}\text { Variation of direction }\left(\text { degree } \mathrm{s}^{-1} \text { ) of the head per }\right. \\
\text { unit time }\end{array}$ & All & 66 \\
\hline
\end{tabular}

These analyses allowed us to assess whether the sound emission rate was also linked to the agonistic events in the males that were competing for the females. The cage consisted of a parallelepiped $(20 \times$ $15 \times 15 \mathrm{~cm}$ ) of plastic net (mesh size $1 \mathrm{~cm}$ ) that allowed for circulation of water inside and outside the cage, and also allowed the male to see the female in the tank. A total of 12 trials with 1 caged female (in either pre-copulatory or control condition) with 1 or 2 males outside the cage were carried out: 3 trials with a caged pre-copulatory female and 1 male, 3 trials with a caged control female and 1 male, 3 trials with a caged pre-copulatory female and 2 males, and 3 trials with a caged control female and 2 males. For the caged trials, $24 \mathrm{~h}$ of audio and video data were analysed.

\section{Audio and video monitoring system}

To avoid disturbing the animals inside the experimental tank, the audio-video monitoring and recording equipment was installed on a table placed $3 \mathrm{~m}$ from the tank. The acoustic behaviour of the crabs and the baseline noise of the tank were recorded using a calibrated hydrophone (model 8104; Bruel \& Kjer) with a sensitivity of $205.6 \mathrm{~dB}$ re $1 \mathrm{~V} \mathrm{~Pa}^{-1} \pm 4.0 \mathrm{~dB}$ in the $0.1 \mathrm{~Hz}$ to $80 \mathrm{kHz}$ frequency band. The hydrophone was placed at a depth of $0.2 \mathrm{~m}$, close to the tank wall $(0.1 \mathrm{~m})$. The equipment was connected to a digital acquisition card (USGH416HB, Avisoft Bioacoustics, septate with 40 dB gain) managed by a dedicated Avisoft Recorder USGH software (Avisoft Bioacoustics). The signals were acquired at 300 kilo- 
samples $\mathrm{s}^{-1}$ at 16 bits and analysed by the AvisoftSASLab Pro software (Avisoft Bioacoustics).

A video system was used to monitor the behaviours of the crabs, and was synchronised with the acoustic monitoring system. The videos for behavioural monitoring were collected using an analog camera (model PC-IRB23WP, PCBOX, lens: $3.6 \mathrm{~mm}$, sensor: ${ }^{1 / 4^{\prime}} \mathrm{CCD}$, effective picture NTSC: $510 \times 492$, horizontal resolution 420 TV lines) placed on the top of the experimental tank $0.7 \mathrm{~m}$ from the water surface (see Fig. 1). The camera was linked to a computer, and the files were managed by Nero Vision 12.0 (Nero Development \& Services).

\section{Acoustic analysis}

To individuate the sounds emitted by crabs, an operator visualized the oscillogram and spectrogram of all the acoustic files in wave format from all trials. To avoid counting sounds produced by accidental contact between animals, we considered only sounds with a regular pulse rate and with 3 or more pulses. For the acoustic parameter measurements, we selected the sounds that did not show any overlap with noise generated accidentally by crabs.

For each selected sound, we measured the following parameters: (1) the number of pulses in the pulse train; $(2)$ the pulse train duration (s), determined as the interval time between the first and last pulse of the pulse train; (3) the pulse rate $(\mathrm{Hz})$, determined as the ratio of the number of pulses and the duration of the pulse train; (4) the 1st and 2nd peak frequencies $(\mathrm{Hz})$, which were the frequencies corresponding to the highest and second highest amplitudes respectively, determined from the spectrogram (sampling frequency $300 \mathrm{kHz}$; FFT length: 512 points; resolution: $586 \mathrm{~Hz}_{\text {; }}$ window: FlatTop); (5) the 1st and 2nd peak amplitudes (dB re $1 \mu \mathrm{Pa}$ ), the amplitude of the 1 st and 2nd peak frequencies determined in the spectrogram; (6) the $3 \mathrm{~dB}$ bandwidth, determined as the frequency range within which the power spectrum density was above half of its maximum value (that is, above $-3 \mathrm{~dB}$ relative to the peak); and (7) the $10 \mathrm{~dB}$ bandwidth, determined as the frequency range within which the power spectrum density was above $10 \mathrm{~dB}$ of its maximum value.

\section{Video analysis}

A visual continuous sampling procedure (i.e. each observed event annotated in a sampling table) was only applied for the behaviours 'chela spread', 'agonistic fight', 'contact approach' and 'contact cage' (see Table 1), and was performed because the automated software was unable to identify and measure these specific behavioural events. After this phase, the videos were analysed with EthoVision XT 9.0 software (Noldus Information Technology). The experimental arena was calibrated across the bottom wall of the tanks, and the calibration axes were placed to designate the origin $(0,0)$ at the tank centre. Group trials were analysed by adopting the Social Interaction Module (SIM). The SIM is an addon to the EthoVision XT program that enables the detection of multiple unmarked animals in a social context. It is capable of assessing the crabs' shoaling behaviour by simultaneously tracking all specimens and recording dynamic changes in the social behaviour between the subjects. The analysis was performed on each frame to distinguish the object(s) from the background on the basis of their greyscale/ brightness values and by extracting the coordinates of the geometric centre and surface area for each object in each frame. The data were acquired at 25 frames s$^{-1}$. In all experiments, the subject loss due to misdetection by video-tracking software was $<2 \%$. Behavioural data were exported to Microsoft Excel to generate the total and per-minute plots for each endpoint. We then pooled the behaviours into 10 min sections. See Table 2 for a description of all behavioural states and events that were evaluated.

\section{Statistical analysis}

The data were tested for goodness-of-fit to the normal distribution using a chi-squared test. Different distributions in behavioural data were observed; therefore, nonparametric tests were applied to compare the different values among the trials.

To determine differences in acoustic parameters between male and female sounds, we used a MannWhitney $U$-test (sex condition: male or female). In the caged trials, the Mann-Whitney $U$-test was also used to compare all behavioural variables measured in the 1- or 2-male trials (condition: 1 or 2 males), and with different female reproductive status (condition: precopulatory or control females).

A Kruskal-Wallis test was used to assess if behavioural parameters among single animals (conditions: male, female control, female pre-copulatory) and among animals in groups (conditions: males, females control, female pre-copulatory, mixed sex) were different. Moreover, a comparison between single and 
grouped animals was performed to determine any differences in sound emission rate using a MannWhitney $U$-test (conditions: single, group).

The statistical tests were performed on data collected every $1 \mathrm{~min}$ for the total experimental time procedure. Results were considered statistically significant at $\mathrm{p}<0.05$. All statistical analyses were performed using the STATISTICA 7.0 software package (StatSoft).

\section{RESULTS}

\section{Acoustic signals}

The mean power spectrum of signals from 10 crabs (from the mixed sex group trial recordings) was distinguishable from the background noise of the experimental tank (Fig. 2a). An oscillogram and spectrogram of a signal from a male are provided as examples (Fig. 2b).

A total of 207 sounds were recorded during all trials. We selected 82 signals from the mono-sexual group or single animals to measure the acoustic parameters, distinguishing males and females (without any distinction between pre-copulatory or control females) (Table 2). Males and females showed similar acoustic characteristics. However, significant differences were found in the 1st peak frequency, its amplitude and the $10 \mathrm{~dB}$ bandwidth. Specifically, the median values of the 1 st peak frequency was lower in males than females $(3.5$ and $4.8 \mathrm{kHz}$ respectively; Mann-Whitney $U$-test, p < 0.05). Conversely, the median values of the 1 st peak frequency amplitude was higher in males than in females (127.0 and $123.5 \mathrm{~dB}$ re $1 \mu \mathrm{Pa}$ respectively; Mann-Whitney $U$-test, $\mathrm{p}<0.05)$. In addition, males presented higher median values than females for the $10 \mathrm{~dB}$ bandwidth $(5.55$ and $2.90 \mathrm{kHz}$; MannWhitney $U$-test, $\mathrm{p}<0.05)$.

\section{Single trials}

Individual crabs were monitored for $18 \mathrm{~h}$. Acoustic analysis showed that 2 out of 3 pre-copulatory females emitted signals ( 3 in $6 \mathrm{~h}$ ); conversely, males and control females (in a total of $12 \mathrm{~h}$ ) did not produce any sounds. Video analysis showed that the control females presented significantly higher velocity values than the pre-copulatory females and higher mobility values than the males (Fig. 3) (Kruskal-Wallis multiple comparison test, $\mathrm{p}<0.05)$.

\section{Group trials}

In the group trials, both the males and females produced acoustic signals. Grouped animals produced pro capite a higher number of sounds than single animals. Grouped males emitted the highest number of sounds (Mann-Whitney $U$-test, p < 0.05) compared to females (considering control and precopulatory females together). The mean $( \pm \mathrm{SE})$ number of signals per specimen in 10 min was $0.30 \pm$ 0.05 and $0.13 \pm 0.03$ for males and females respectively (considering control and pre-copulatory females together). The mixed sex groups presented a higher number of signals during the night than during the day (Mann-Whitney $U$-test, p $<0.04$; mean no. of signals per $10 \mathrm{~min}: 0.53 \pm 0.11$ and 0.30 \pm 0.08 respectively) .

The grouped males showed lower values of velocity and higher mobility compared to the other 3 group types (Kruskal-Wallis multiple comparison test, $\mathrm{p}<0.05$ ) (Fig. 4). The pre-copulatory female and mixed-sex groups had higher values of turn angle and angular velocity (Kruskal-Wallis multiple comparison test, $\mathrm{p}<0.05)$. The mixed groups had higher values of mobility compared to the female groups (Kruskal-Wallis multiple comparison test, $\mathrm{p}<0.05$ ).

\section{Caged trials}

The signal analysis performed in the caged trials (with 1 male and 2 males) showed a significantly higher number of sound emissions when a precopulatory female was present (Fig. 4a).

With 1 male. The mean $( \pm \mathrm{SE})$ number of acoustic signals per individual in 10 min was higher in the trials with a pre-copulatory female than a control female $(0.28 \pm 0.09$ and $0.03 \pm 0.02$ respectively; MannWhitney $U$-test, $\mathrm{p}<0.01)$. In the other behavioural events and states, no significant differences were observed between the trials with the control or precopulatory female with the exception of the contact cage event, which was higher in the trial with the pre-copulatory female (Fig. 4d).

With 2 males. The mean $( \pm \mathrm{SE})$ number of signals per individual in 10 min was significantly higher in the trials with a pre-copulatory female compared with the control female (Mann-Whitney $U$-test, p < $0.01)$, with values of $0.24 \pm 0.05$ and $0.07 \pm 0.02$ respectively. In the trials with the caged pre-copulatory female, the number of acoustic signals per animal did not change if we considered the trials with 1 or 2 males (see the previous sub-section) (Fig. 4a). 

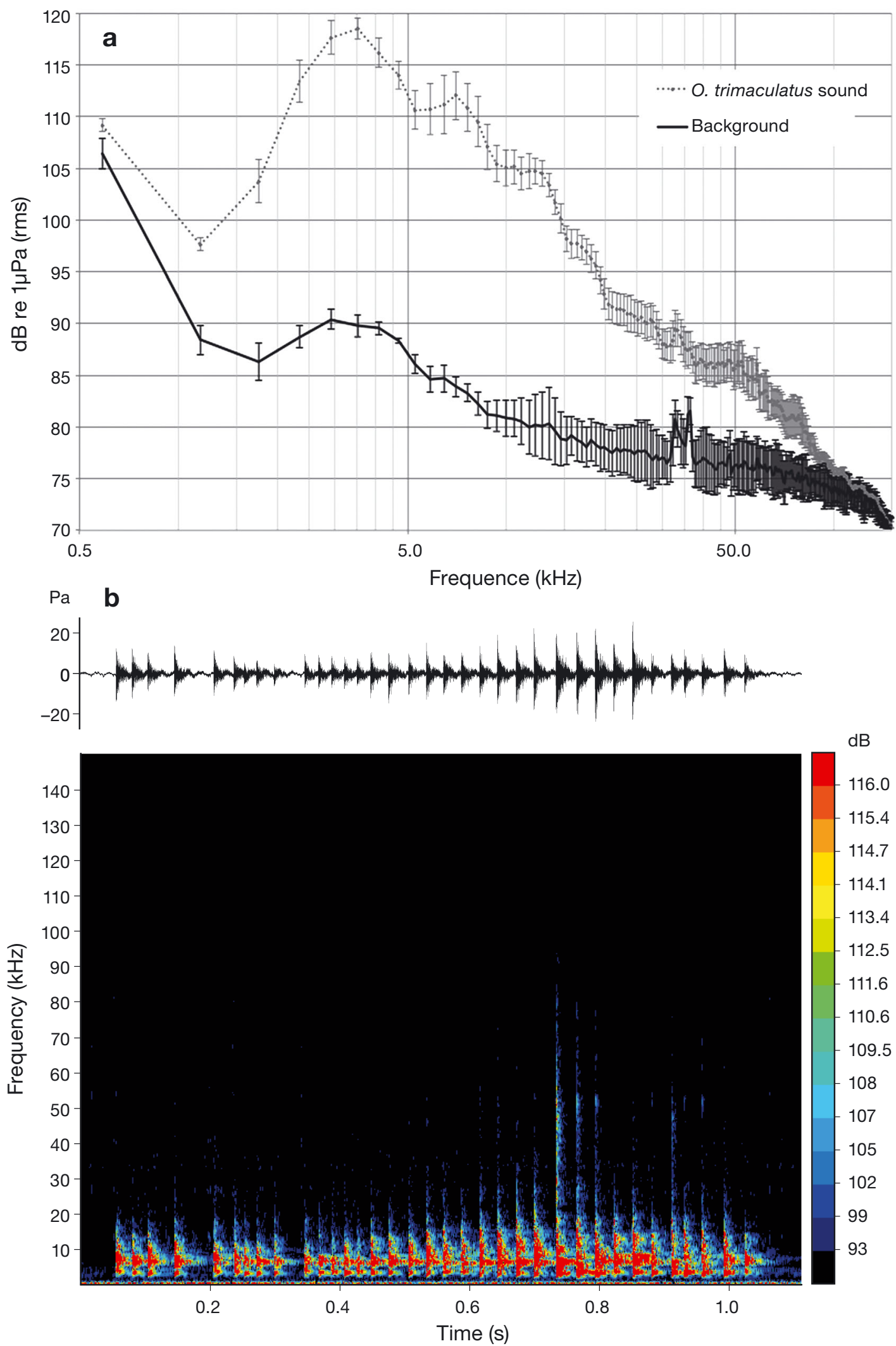

Fig. 2. (a) Mean ( \pm SE) power spectrum of 10 Ovalipes trimaculatus signals compared with the background noise of the experimental tank, and (b) the oscillogram (top) and spectrogram (bottom) of a signal from a male. Colour scale: $\mathrm{dB}$ re $1 \mu \mathrm{Pa}(\mathrm{rms})$ 
Table 2. Comparison between acoustic parameters of sound (median \pm 10 th to 90 th percentiles) produced by male $(\mathrm{n}=54)$ and female $(\mathrm{n}=28$ ) (considering control and pre-copulatory females together) Ovalipes trimaculatus, and associated p-values based on the non-parametric Mann-Whitney $U$-test. Significant $(\mathrm{p}<0.05)$ values in bold

\begin{tabular}{|lcccccc|}
\hline & \multirow{2}{*}{ Units } & \multicolumn{2}{c}{ Males } & \multicolumn{2}{c}{ Females } \\
Parameter & & Median & $10-90 \%$ & Median & $10-90 \%$ & 0.55 \\
No. pulses per rasp & no. & 11.0 & $4.0-35.0$ & 8.0 & $4.0-25.0$ \\
Rasp duration & $\mathrm{s}$ & 0.150 & $0.070-0.910$ & 0.145 & $0.055-0.445$ \\
Pulse rate & $\mathrm{Hz}$ & 57.1 & $31.0-105.0$ & 52.9 & $33.7-97.8$ & 0.60 \\
1st peak frequency & $\mathrm{kHz}$ & 3.5 & $1.1-7.6$ & 4.8 & $3.1-11.4$ \\
2nd peak frequency & $\mathrm{kHz}$ & 9.6 & $4.1-19.3$ & 9.2 & $3.5-15.8$ & $\mathbf{0 . 0 3}$ \\
1st peak frequency amplitude & $\mathrm{dB} \mathrm{re} \mathrm{1 \mu Pa}$ & 127.0 & $115.0-139.0$ & 123.5 & $113.5-132.0$ & $\mathbf{0 . 0 3}$ \\
2nd peak frequency amplitude & $\mathrm{dB} \mathrm{re} \mathrm{1 \mu Pa}$ & 119.0 & $108.0-130.0$ & 117.0 & $108.0-126.0$ & 0.07 \\
Bandwidth 3 dB & $\mathrm{kHz}$ & 1200 & $1100-4700$ & 1100 & $600-1200$ & 0.34 \\
Bandwidth 10 dB & $\mathrm{kHz}$ & 5550 & $2900-11650$ & 2900 & $2300-4100$ & $\mathbf{0 . 0 3}$ \\
\hline
\end{tabular}

The comparison of the other behavioural states and events showed significant differences (Mann-Whitney $U$-test, $\mathrm{p}<0.01$ ) between the trials. In particular, with a caged pre-copulatory female, the males showed higher values of chela spread, velocity, mobility, and high mobility (Mann-Whitney $U$-test, $\mathrm{p}<0.01$ ) (Fig. 4b,c,e,f).

\section{DISCUSSION}

The analysis of our data showed that both sexes of Ovalipes trimaculatus produced sounds. Males and females presented a similar sound structure that consisted of a multi-pulsed 'rasp' (Fig. 2, Table 1), which was similar in structure to other rasps produced by stridulating crustaceans (Patek 2001, Buscaino et al. 2011a). For both sexes, the 1st and 2nd peaks in frequencies fell within the human audible range (below $10 \mathrm{kHz}$ ); however, ultrasound frequencies were present until $100 \mathrm{kHz}$ (see the power spectrum in Fig. 2a). These higher spectral energies are typical of a stridulation mechanism if we exclude the 'rapping' among them, namely striking the claw against the substrate (Popper et al. 2001). This was avoided in our study by positioning a rubber substrate on the bottom of the tank. Even though male and female sounds revealed similar structures, 3 significant differences in acoustic characteristics between the sexes were found. In particular, in females the median values of the 1 st peak frequency and 1st peak frequency amplitude were significantly higher and lower, respectively, than those of the males. Moreover, males produced a sound with a slightly larger bandwidth with respect to females. Although there are exceptions, crustacean males generally grow faster and larger than females (Aiken 1980), and these growth differences are particularly evident in the secondary sexual characters such as the chelae, abdomen and first pleopods (Hartnoll 1974, Vallina et al. 2014). In this genus, stridulation is hypothesized to occur by rubbing the appendages against the carapace (Stephenson 1969). Therefore, it is possible that our results may be correlated with the differences in body size between males and females, because an increase in the size of the soundproducing apparatus should permit the production of louder signals, and consequently less acuteness in frequency (Patek \& Oakley 2003).

In the single trial type, in which we had the opportunity to associate sound emission with a specific movement of an animal in the tank, we did not observe any large movement before, during or after sound emission, and the specimen did not walk. However, the quality of the videos did not allow us to assess if there were small movements of the legs against the chela to confirm the stridulation mechanism (GuinotDumortier \& Dumortier 1960, Stephenson 1969, Parker et al. 1998). In some crustacean decapod species, sound production results from an accidental event due to the movement of the animal with respect to the bottom, and/or is associated with a behavioural event such as a tail flip (e.g. in Palinurus or Procambarus species) (Buscaino et al. 2011a,b, 2012). However, in $O$. trimaculatus the production of sound did not appear to be correlated with large movements, and thus we assumed that the production of sound was not an accidental event. This hypothesis was confirmed by our results because the males in groups presented lower values of locomotor parameters compared to females, yet had higher sound emission rates.

The mixed sex groups showed a higher rate of sound emission during the night compared to the day. This result is in agreement with other studies of aquatic crustaceans, which have revealed the ten- 

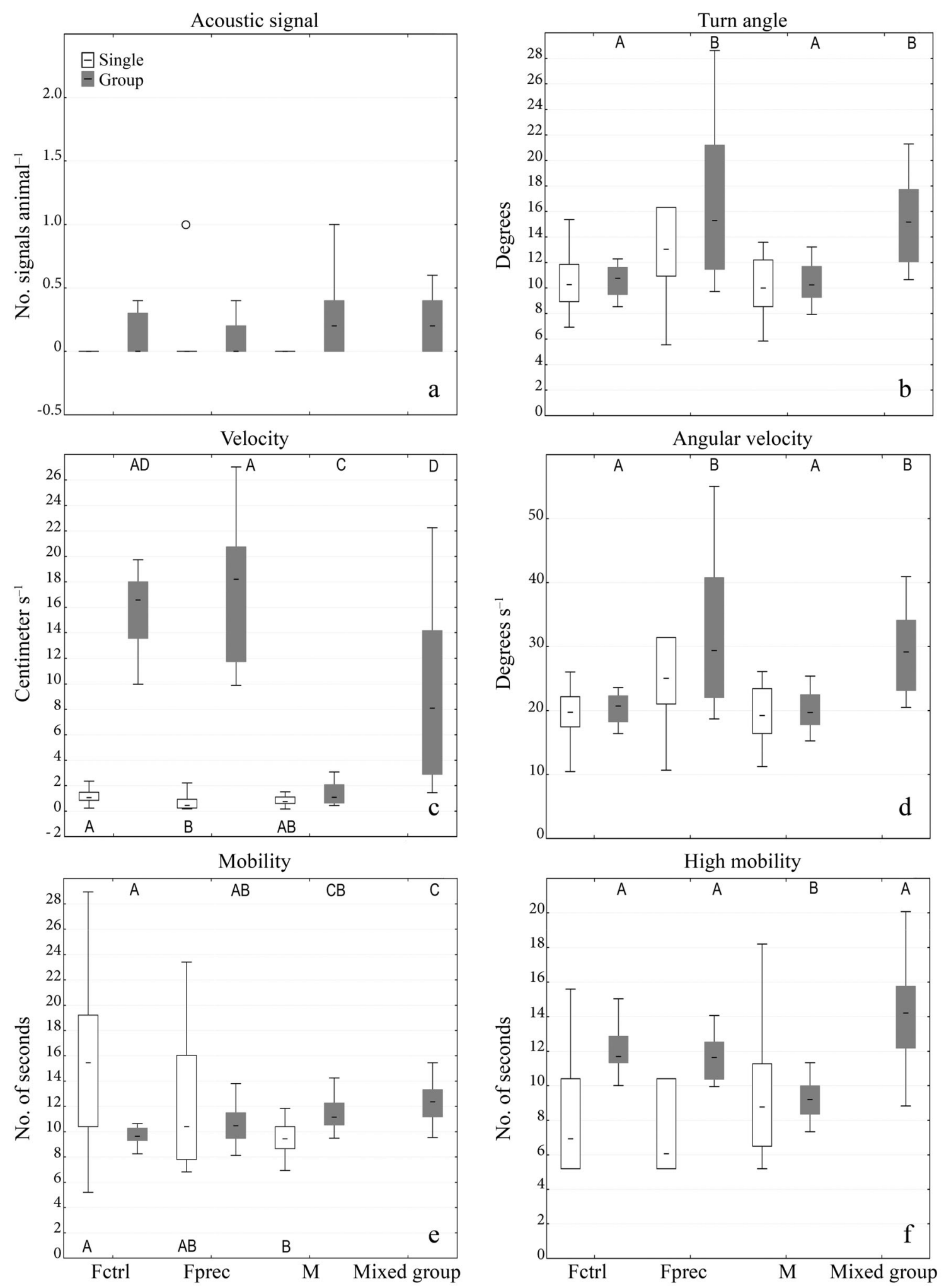

Fig. 3. Behavioural events and states for single and group trials per animal in 10 min, showing median \pm 25 th to 75 th percentiles; error bars: $95 \%$ CI. In (a), the symbol (o) refers to an outlier. Fctrl: control female; Fprec: female in pre-copulatory condition; M: male; Mixed group: group with 3 males and 2 pre-copulatory females. The different letters indicate significant differences among the trials: below for significant differences within grouped animals, above for significant differences between single animals. For example, in (b) the 'A' above indicates significant differences of group Fctrl with regard to the group Fprec and Mixed group but no significant difference with regard to group $\mathrm{M}$ 

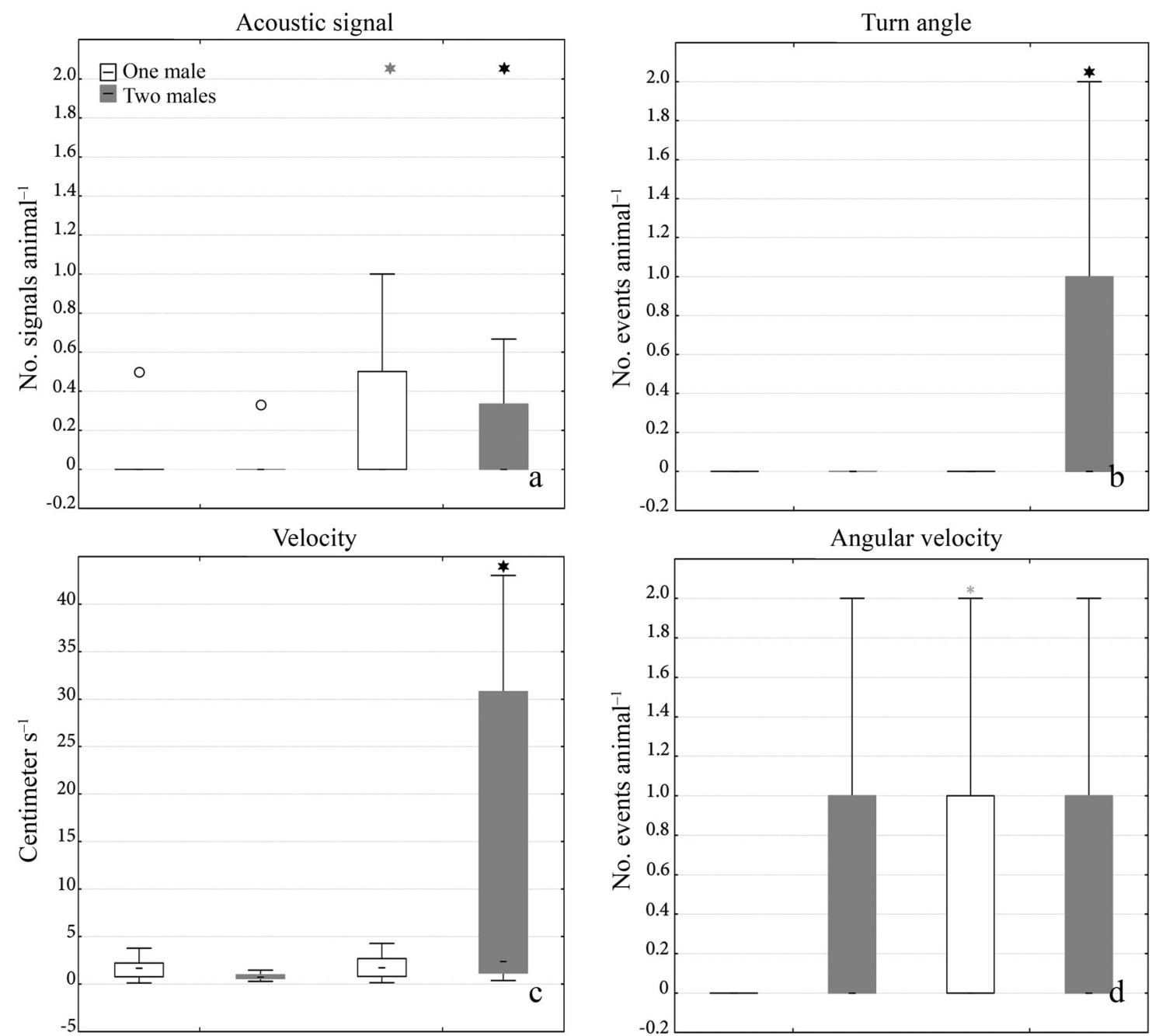

Angular velocity
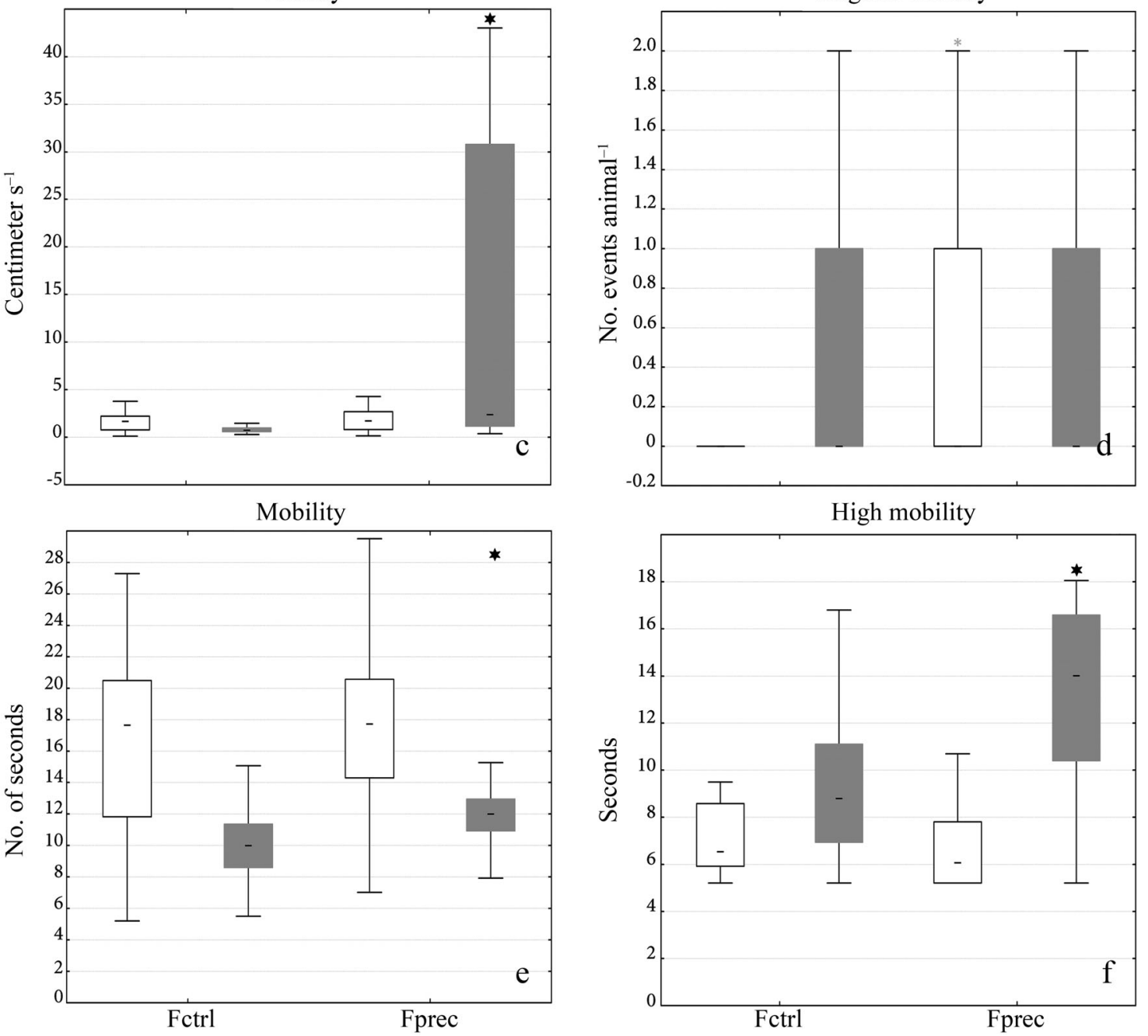

Fig. 4. Male crab behavioural events and states per $10 \mathrm{~min}$ in the presence of caged female (Fprec: pre-copulatory female; Fctrl: control female). For the acoustic events, the value refers to 1 animal without the distinction of sex. The plots concern only the behaviours in which differences between control (Fctrl) and test (Fprec) were significant. Median \pm 25 th to 75 th percentiles; error bars: $95 \%$ CI. Outliers $\left({ }^{\circ}\right)$ are presented only for the acoustic signal graph. Asterisks $\left({ }^{*}\right)$ represent significant differences between control and test conditions (grey asterisk for significant differences within the 1-male trials; black for significant differences within 2-male trials) 
dency to increase sound emission rate and locomotor activities at night (Buscaino et al. 2012, Giacalone et al. 2015). In animals that are active nocturnally, such as Ovalipes spp. (Takahashi \& Kawaguchi 2001), visual signals are of limited value, and thus vocal and chemical cues could be used in mate attraction. During the night, sexual partner selection by $O$. trimaculatus could be based on the partner's perceptible signals, such acoustic or chemical.

In brachyurans, most acoustic studies have focused on semi-terrestrial crabs (e.g. Sesarminae, Ocypodidae, Gecarcinidae) (Parker et al. 1998, Boon et al. 2009). In crabs, sounds can play an important role in courtship (Popper et al. 2001), and most of the current literature on mating behaviour has primarily focused on the use of signals by males to attract females. These signals were recorded, especially during phases of the lunar cycle, when females were receptive to sounds (Popper et al. 2001). Salmon (1967) showed that males of Ocypodidae (Uca rapax and $U$. speciosa) produce sounds to attract receptive females to their burrows. In the current study, analysis of the single trials indicated that only females in a pre-copulatory state produced sounds. We therefore assume that females in the pre-copulatory phase can use acoustic signals, probably in addition to chemical ones, to attract males. The acoustic, chemical and visual signals could all be cues for intraspecific communication in crustacean species, and the prevalence of one with respect to the others could vary as a function of species distribution and/or ecological condition (i.e. day-nighttime, current, predation risk, sexual stage, presence of sexual partner or conspecifics that compete for the same resources).

In the group trials, control females, males and precopulatory females emitted acoustic signals. In particular, a significantly higher number of emissions were found in the male groups compared to the other groups and the single trials. This result was in agreement with another study conducted with Ocypodidae that revealed that undisturbed males produced sounds at relatively slow rates, but when stimulated by sounds of other crabs or by the nearby movements of neighbouring specimens, the rates of sound production could more than double (Popper et al. 2001). Moreover, the male groups presented lower values of locomotor behaviours, such as velocity and high mobility, than the control and pre-copulatory female groups. In mobile marine species, such as paddle crabs, locomotor movement is an important link between the behaviour of individuals and ecological processes (Herrnkind 1983, Spanier et al. 1988, Lawton \& Lavalli 1995, Giacalone et al. 2006). In our study, the single pre-copulatory females presented lower velocity values than the control females. These results are in agreement with the results found for Uca pugilator, in which individual females in the precopulatory condition occupied temporary burrows for approximately $2 \mathrm{wk}$, presumably to accumulate reserves sufficient to produce a clutch of eggs (Christy \& Salmon 1984, Turner et al. 2003) and for muscle growth (Medici et al. 2006). In this way, their locomotor activity was considerably lower than females with the basal condition.

In addition, the results obtained from the group trials with the pre-copulatory females (see the mixed groups and the mono-sexual pre-copulatory female groups) had higher rates of turn angle and angular velocity (Fig. 3b,d). These movements are not finalized to linear displacement in space and could be associated with the search/approach orientation phases. In the presence of pre-copulatory females, higher rates of turn angle of males and/or females could indicate a specific interest in the approach of the sexual partner. Additionally, an increase in angular velocity could favour a better perception of chemical stimuli produced by the female during the pre-copulatory phase.

In the caged trials with both 1 and 2 males, the number of sounds was higher when a female in the pre-copulatory condition was present. However, the emission sound rate did not change between the 1 - or 2-male trials in the presence of a pre-copulatory female. Additionally, in the 2-male trials the agonistic parameter 'chelae spread' and some locomotor values increased in the presence of a pre-copulatory female. These 2 results led us to consider that in these crabs, sound emissions are directly connected to sexual activity and not to agonistic behaviours. Considering that in the single trials, the pre-copulatory females produced a higher number of signals than the control females and the males, we hypothesized that in the caged trials, the pre-copulatory females emitted a higher number of acoustic signals to attract males. Otherwise, the male (in the presence of a pre-copulatory female) can be elicited by the female's chemical signals to emit sounds and attract the female to mate. However, in our caged trials, it is unknown whether the males or females produced the sounds.

Crabs are mobile species, and their movements are highly related to ecological and biological aspects. In particular, territoriality, nomadism and migration are locomotor behaviours that have implications for the survival, growth and reproduction of decapod crustaceans (Herrnkind 1983, Spanier et al. 1988, Lawton \& Lavalli 1995). The results of our 2-male caged trials showed a significant increase in locomotor behav- 
iours such as mobility, high mobility and velocity when females in the pre-copulatory condition were present. Many genera of crabs, including the portunid O. trimaculatus, can only copulate immediately following the moulting period, when the female has a soft carapace (Crothers 1967, Haddon 1994). Male paddle crabs are regularly found carrying and defending pre-moult females (Haddon 1994). Haddon (1994) documented males of the New Zealand paddle crab Ovalipes catharus carrying pre-moult females under their body for up to $8 \mathrm{~d}$ prior to the female moulting. This pre-moult guarding by the males should increase the chances of a female finding a suitable partner in the $4 \mathrm{~d}$ available before her newly secreted exoskeleton becomes too hard. At the same time, immediately post-moult, crabs were extremely vulnerable to cannibalism (Haddon 1994), so that copulating males vigorously defended their partners from attacks by other paddle crabs (Haddon 1994). This evidence suggests that male O. trimaculatus may increase their locomotor behaviour in the presence of other males in order to protect his potential partner for copulation. This was defined by Christy (1987) as 'pure search and interception' that is, searching for or intercepting females and attempting to mate with those they encounter.

This study was the first characterization of the acoustic parameters of sounds emitted by $O$. trimaculatus, and revealed differences between males and females. The sound emission rate was higher in grouped animals (relative to individuals housed alone) and was also higher during the night (relative to the day). Sound emission did not occur as a result of accidental events correlated to locomotor activities, and seemed to play a role in intraspecific communication related to sexual attraction.

Acknowledgements. This study was possible because of the will of Lobo Oresanz. In this man, a special mixture of humanity, humor and scientific vision made feasible what was unlikely. This study was supported by the RECOMPRA project - Reef ECOlogy and design of Marine PRotected Areas FP7-PEOPLE-2011-IRSES - Marie Curie Action 'International Research Staff Exchange Scheme'.

\section{LITERATURE CITED}

Aiken DE (1980) Molting and growth. In: Cobb SJ, Phillips BF (eds) The biology and management of lobsters, Vol 1. Academic Press, New York, NY, p 91-147

Ali MA (1987) Nervous systems in invertebrates. Plenum Press, New York, NY

Arnaud P, Beurois J, Noel P (1972) Portunidae et Grapsidae des Îles Saint Paul et Amsterdam, Ocean Indean (Decapoda, Brachyura). Beaufortia 20:7-14

Asakura A (2009) The evolution of mating systems in deca- pod crustaceans. In: Martin JW, Crandall KA, Felder DL (eds) Decapod crustacean phylogenetics. CRC Press, Boca Raton, FL, p 121-82

$\mathrm{Au}$ WWL (1993) The sonar of dolphins. Springer-Verlag, New York, NY

Boon PY, Yeo DCJ, Todd PA (2009) Sound production and reception in mangrove crabs Perisesarma spp. (Brachyura: Sesarmidae). Aquat Biol 5:107-116

Boschi EE, Fischbach CE, Iorio MI (1992) Catálogo ilustrado de los crustáceos estomatópodos y decápodos marinos de Argentina. Frente Marít 10:7-94

Bouwma PE, Herrnkind WF (2009) Sound production in Caribbean spiny lobster Panulirus argus and its role in escape during predatory attack by Octopus briareus. NZ J Mar Freshw Res 43:3-13

Buscaino G, Filiciotto F, Gristina M, Bellante A and others (2011a) Acoustic behaviour of the European spiny lobster Palinurus elephas. Mar Ecol Prog Ser 441:177-184

Buscaino G, Filiciotto F, Gristina M, Buffa G and others (2011b) Defensive strategies of European spiny lobster Palinurus elephas during predator attack. Mar Ecol Prog Ser 423:143-154

Buscaino G, Filiciotto F, Buffa G, Di Stefano V and others (2012) The underwater acoustic activities of the red swamp crayfish Procambarus clarkii. J Acoust Soc Am 132:1792-1798

> Buscaino G, Buffa G, Filiciotto F, Maccarrone V and others (2015) Pulsed signal properties of free-ranging bottlenose dolphins (Tursiops truncatus) in the Central Mediterranean Sea. Mar Mamm Sci 31:891-901

Busnel RG (1963) Acoustic behaviour of animals. Elsevier, New York, NY

Christy JH (1987) Competitive mating, mate choice and mating associations of brachyuran crabs. Bull Mar Sci 41: 177-191

> Christy JH, Salmon M (1984) Ecology and evolution of mating systems of fiddler crabs (genus Uca). Biol Rev Camb Philos Soc 59:483-509

Crane J (1966) Combat, display and ritualization in fiddler crabs (Ocypodidae, genus Uca). Philos Trans R Soc Lond B 251:459-472

Crothers JH (1967) The biology of the shore crab Carcinus maenas (L.). The background-anatomy, growth and life history. Field Studies 2:407-434

de Melo GAS (1996) Manual de identificação dos Brachyura (caranguejos e siris) do litoral brasileiro. Pleiadi, São Paulo

> de Vincenzi G, Filiciotto F, Maccarrone V, Mazzola S, Buscaino G (2015) Behavioural responses of the European spiny lobster Palinurus elephas (Fabricius, 1787), to conspecific and synthetic sounds. Crustaceana 88:523-540

> Dellatorre FG, Pisoni JP, Barón PJ, Rivas AL (2012) Tide and wind forced nearshore dynamics in Nuevo Gulf (Northern Patagonia, Argentina): potential implications for cross-shore transport. J Mar Syst 96-97:82-89

- Giacalone VM, D'Anna G, Pipitone C, Badalamenti F (2006) Movements and residence time of spiny lobsters, Palinurus elephas released in a marine protected area: an investigation by ultrasonic telemetry. J Mar Biol Assoc UK 86:1101-1106

Giacalone VM, Barausse A, Gristina M, Pipitone C, Visconti V, Badalamenti F, D'Anna G (2015) Diel activity and short-distance movement pattern of the European spiny lobster, Palinurus elephas, acoustically tracked. Mar Ecol 36:389-399

Greenfield MD (2002) Signalers and receivers: mechanisms and evolution of Arthropod communication. Oxford University Press, Oxford 
Guinot-Dumortier D, Dumortier B (1960) La stridulation chez les crabes. Crustaceana 1:117-155

Haddon M (1994) Size-fecundity relationships, mating behaviour, and larval release in the New Zealand paddle crab, Ovalipes catharus (White 1843) (Brachyura: Portunidae). NZ J Mar Freshw Res 28:329-334

> Hartnoll RG (1974) Variation in growth pattern between some secondary sexual characters in crabs (Decapoda Brachyura). Crustaceana 27:131-136

Hazlett BA, Winn HE (1962) Sound production and associated behavior of Bermuda crustaceans (Panulirus, Gonodactylus, Alpheus, and Synalpheus). Crustaceana 4:25-38

Henninger HP, Watson WH (2005) Mechanisms underlying the production of carapace vibrations and associated waterborne sounds in the American lobster, Homarus americanus. J Exp Biol 208:3421-3429

Herrnkind WF (1983) Movement patterns and orientation. In: Vernberg FJ, Vernberg WB (eds) The biology of Crustacea, Vol 7. Academic Press, New York, NY, p 41-105

Imafuku M, Ikeda H (1990) Sound production in the land hermit crab Coenobita purpureus Stimpson, 1858 (Decapoda, Coenobitidae). Crustaceana 58:168-174

Johnson M, Hickmoth L, Aguilar Soto N, Madsen PT (2008) Echolocation behaviour adapted to prey in foraging Blainville's beaked whale (Mesoplodon densirostris). Proc R Soc B 275:133-139

Knowlton RE, Moulton JM (1963) Sound production in the snapping shrimps Alpheus (Crangon) and Synalpheus. Biol Bull (Woods Hole) 125:311-331

Lawton P, Lavalli KL (1995) Postlarval, juvenile, adolescent, and adult ecology. In: Factor JR (ed) Biology of the lobster, Homarus americanus. Academic Press, San Diego, CA, p 47-88

Lindberg RG (1955) Growth, population dynamics and field behavior in the spiny lobster, Panulirus interruptus (Randall). Univ Calif Publ Zool 59:157-248

McLay CL (1988) Brachyura and crab-like Anomura of New Zealand. Leigh Laboratory Bulletin No. 22, Leigh Marine Laboratory, University of Auckland

Medici DA, Wolcott TG, Wolcott DL (2006) Scale-dependent movements and protection of female blue crabs (Callinectes sapidus). Can J Fish Aquat Sci 63:858-871

> Meyer-Rochow VB, Penrose JD (1974) Sound and sound emission apparatus in puerulus and postpuerulus of the western rock lobster (Panulirus longipes). J Exp Zool 189:283-289

Meyer-Rochow VB, Penrose JD (1976) Sound production by the western rock lobster Panulirus longipes (Milne Edwards). J Exp Mar Biol Ecol 23:191-209

Meyer-Rochow VB, Penrose JD, Oldfield BP, Bailey WY (1982) Phonoresponses in the rock lobster Palinurus longipes (Milne Edwards). Behav Neural Biol 34:331-336

Miller PJO, Johnson MP, Tyack PL (2004) Sperm whale behaviour indicates the use of echolocation click buzzes 'creaks' in prey capture. Proc R Soc B 271:2239-2247

Moulton JM (1957) Sound production in the spiny lobster Panulirus argus (Latreille). Biol Bull (Woods Hole) 113: 286-295

Nakamura IT, Inada M, Takeda Y, Hatanaka H (1986) Important fishes trawled off Patagonia. Japan Marine Fishery Resource Research Center, Tokyo

Parker AR, Mckenzie DR, Ahyong ST (1998) A unique form of light reflector and the evolution of signalling in Ovalipes (Crustacea: Decapoda: Portunidae). Proc R Soc B 265:861-867

Editorial responsibility: Christine Paetzold, Oldendorf/Luhe, Germany
Patek SN (2001) Spiny lobsters stick and slip to make sound. Nature 411:153-154

Patek SN, Baio JE (2007) The acoustic mechanics of stickslip friction in the California spiny lobster (Panulirus interruptus). J Exp Biol 210:3538-3546

> Patek SN, Caldwell RL (2006) The stomatopod rumble: low frequency sound production in Hemisquilla californiensis. Mar Freshwat Behav Physiol 39:99-111

- Patek SN, Oakley TH (2003) Comparative tests of evolutionary trade-offs in a palinurid lobster acoustic system. Evolution 57:2082-2100

> Patek SN, Shipp LE, Staaterman ER (2009) The acoustics and acoustic behavior of the California spiny lobster (Panulirus interruptus). J Acoust Soc Am 125:3434-3443

Pinheiro MAA, Fransozo A (1999) Reproductive behavior of the swimming crab Arenaeus cribrarius (Lamarck, 1818) (Crustacea, Brachyura, Portunidae) in captivity. Bull Mar Sci 64:243-253

Popper AN, Salmon M, Horch KW (2001) Acoustic detection and communication by decapod crustaceans. J Comp Physiol A 187:83-89

Retamal MA, Arana PM (2000) Descripción y distribución de cinco crustáceos decápodos recolectados en aguas profundas en torno a las islas Robinson Crusoe y Santa Clara (Archipiélago de Juan Fernández, Chile). Investig Mar 28:149-163

Sal Moyano MP, Gavio MA (2012) Comparison of mating behavior and copulation in male morphotypes of the spider crab Libinia spinosa (Brachyura: Majoidea: Epialtidae). J Crustac Biol 32:31-38

Sal Moyano MP, Silva P, Luppi T, Gavio MA (2014) Female mate choice by chemical signals in a semi-terrestrial crab. J Sea Res 85:300-307

Salmon M (1967) Coastal distribution, display and sound production by Florida fiddler crabs (Genus UCa). Anim Behav 15:449-459

Sastry AN (1983) Ecological aspects of reproduction. In: Vernberg FJ, Vernberg WB (eds) The biology of Crustacea, Vol 8. Academic Press, New York, NY, p 179-270

Simpson SD, Meekan MG, McCauley RD, Jeffs A (2004) Attraction of settlement-stage coral reef fishes to reef noise. Mar Ecol Prog Ser 276:263-268

Spanier E, Tom M, Pisanty S, Almog G (1988) Seasonality and shelter selection by the slipper lobster Scyllarides latus in the southeastern Mediterranean. Mar Ecol Prog Ser 42:247-255

Stephenson W (1969) The morphology of stridulatory structures in the genus Ovalipes Rathbun. Trans R Soc NZ 11: $43-71$

Takahashi K, Kawaguchi K (2001) Nocturnal occurrence of the swimming crab Ovalipes punctatus in the swash zone of a sandy beach in the northeastern Japan. Fish Bull 99:510-515

Turner HV, Wolcott DL, Wolcott TG, Hines AH (2003) Postmating behavior, intramolt growth, and onset of migration to Chesapeake Bay spawning grounds by adult female blue crabs, Callinectes sapidus Rathbun. J Exp Mar Biol Ecol 295:107-130

Vallina M, Sal Moyano MP, Cuartas EI, Gavio MA (2014) Reproductive system and size maturity of the paddle crab Ovalipes trimaculatus (Brachyura: Portunidae) along the Argentine coast. J Crustac Biol 34:357-366

Vinuesa JH (2005) Distribución de crustáceos decápodos y estomatópodos del golfo San Jorge, Argentina. Rev Biol Mar Oceanogr 40:7-21

Submitted: February 23, 2015; Accepted: July 28, 2015

Proofs received from author(s): August 27, 2015 